\title{
Hot spots of ecoacoustics in Greece and the issue of background noise
}

\section{Original paper}

Article history:

Received: 5 March 2018

Accepted: 9 August 2018

Published: 18 December 2018

Check for updates

*Correspondence:

YGM: matsinos@aegean.gr

\section{Peer review:}

Double blind

\section{Copyright:}

(c) 2018 Matsinos and Tsaligopoulos @ (This is an open access article distributed under the Creative Commons Attribution License (CC-BY 4.0), which permits unrestricted use, distribution, and reproduction in any medium, provided the original work is properly cited and its authors credited.

\section{Keywords:}

Natura 2000; ecoacoustics; monitoring network; noise map; isobel map; Kalloni's Bay

\section{Citation:}

Matsinos Y. G., Tsaligopoulos A. (2018). Hot spots of ecoacoustics in Greece and the issue of background noise. Journal of Ecoacoustics. 2: \#U3XBIY. https://doi.org/10.22261/JEA.U3XBIY

\author{
Yiannis G. Matsinos ${ }^{1,{ }^{*}}$, Aggelos Tsaligopoulos ${ }^{1}$
}

${ }^{1}$ Acoustic Ecology Laboratory, Department of Environment, University of the Aegean, 81100 Mytilene, Greece

\begin{abstract}
Biodiversity monitoring and assessment across a variety of gradients, could be achieved with the aid of the ecoacoustics discipline. Acoustic monitoring approaches can provide results regarding the species richness of birds, bats, frogs and insects including cicadas (Cicadoidea) and katydids (Tettigoniidae) with results similar to the ones provided by classical ecological methods (e.g. visual point count methods). The risk of extinction of several species has led to the creation of the Natura 2000 Network in the European Union's territory. Greece provides a number of 202 Special Protection Areas (SPA's) and 241 Sites of Community Importance (SCI), 239 of which are considered as Special Areas of Conservation (SAC). The specific areas provide both, an opportunity for ecoacoustics practice and an opportunity for ecoacoustic research. Even though the specific field of ecology has proven to be a valuable biodiversity assessment tool, areas that provide a variety of ecoacoustic events are yet to be documented. The goal of the specific article is to highlight these special conservation areas and propose a monitoring network using the non-invasive approach of ecoacoustics. For the specific research, the Greek protected areas were visualized in order to highlight sonotopes and soundtopes worthy of future research. Finally, in order to highlight the neglected issue of background noise regarding conservation efforts, the Kalloni's salt pans were selected as a case study area. Noise measurements and sound recordings were conducted. Furthermore, noise and sound maps were created, in order to visualize the effects of noise.
\end{abstract}

\section{Introduction}

The geographic coverage of extant biodiversity monitoring programs is insufficient and uneven. Monitoring schemes are typically not implemented at regional scales and few deliver long-term data, making it difficult to monitor biodiversity change across space and time (Buckland and Johnston, 2017). The documentation and quantification of biodiversity alterations, still remains a challenge mainly due to the absence of a common monitoring standard (Turak et al., 2017).

Biodiversity monitoring is essential for both regional and global scale, so that biodiversity responses to environmental change can be measured (Proença et al., 2017). The European Union (EU) has created the Natura 2000 network of Protected Areas (PA), in order to protect species diversity and its habitats (Evans, 2012). The network that includes terrestrial, freshwater and marine ecosystems stretches across all $28 \mathrm{EU}$ countries, representing around $18 \%$ of the total land EU surface. Natura 2000 sites are selected with the aim of ensuring the long-term survival of species and habitats, protected under the Birds and the 
Habitats Directive. Furthermore, the national land coverage of Natura 2000 sites (Figure 1) varies from about $9 \%$ to almost 38\% depending on the countries (European Commission, 2014).

In Greece the PA's cover about the $19 \%$ of the total land coverage. Greek natural areas of specific ecological importance (forests, wetlands etc.) were identified and placed under special protection (Natura, 2000). Additionally, numerus cultural landscapes that are defined as land areas that have been sculpted by traditional human land-use (Jones et al., 2015; Vlami et al., 2017) are under protection. Especially, the Mediterranean basin stands as a global hotspot of biodiversity (Barredo et al., 2016). Furthermore, Important Bird Areas (IBAs) are essential sites for bird conservation due to the fact that they hold significant populations of one or more globally or regionally threatened endemic bird species. Amongst the 14 administrative regions of Greece, there have been identified 196 Important Bird Areas, hosting various species and sites for breeding, passage and wintering (Important Bird Areas, 2018).

Traditional biodiversity assessment techniques could be financially challenging, time consuming and eventually pose as impediments to conservation efforts. The advantage of using sound as a proxy for biodiversity assessment is that it could be recorded remotely, autonomously and relatively inexpensively. Techniques such as rapid biodiversity assessment decrease the amount of effort necessary to assess the species richness and diversity of an ecosystem, by focusing on several key species. Acoustic biodiversity indices such as the Acoustic Complexity Index (ACI) could be easily computed and correlated to species richness. Apart from the creation of an archive considering the biodiversity status of an area, acoustic biodiversity monitoring is a non-intrusive technique and has the potential for long term monitoring of ecosystems.

The use of environmental sound as a quantifiable metric, from which ecological information could be extracted, is a valuable tool regarding ecological research. A recent "change of scale" in bioacoustics has led to the creation of the ecoacoustics discipline that zoom's out on sounds produced by communities, considering the soundscape in its entirety (Sueur et al., 2014). Diverse soundscapes and landscapes retain different acoustic properties. Closed habitats like forests, with dense foliage and high vegetation include multiple surfaces for sound wave absorption and reverberation, hence signaling weakens (Ramsier et al., 2012).

The ecoacoustic discipline holds an important role in biodiversity assessment, due to the fact that it could detect species of interest and estimate the species acoustic diversity variations over time and space. Furthermore, the anthropogenic influence/pressure in the habitats under consideration, could be revealed with the use of ecoacoustics indices and provide valuable information regarding the biodiversity levels. Ecoacoustics refer to the ecological characteristics of sound in a wide spatio temporal scale, in order to address environmental issues similar to climate change and biodiversity assessment using soundscape data. As a scientific discipline it is closely related to

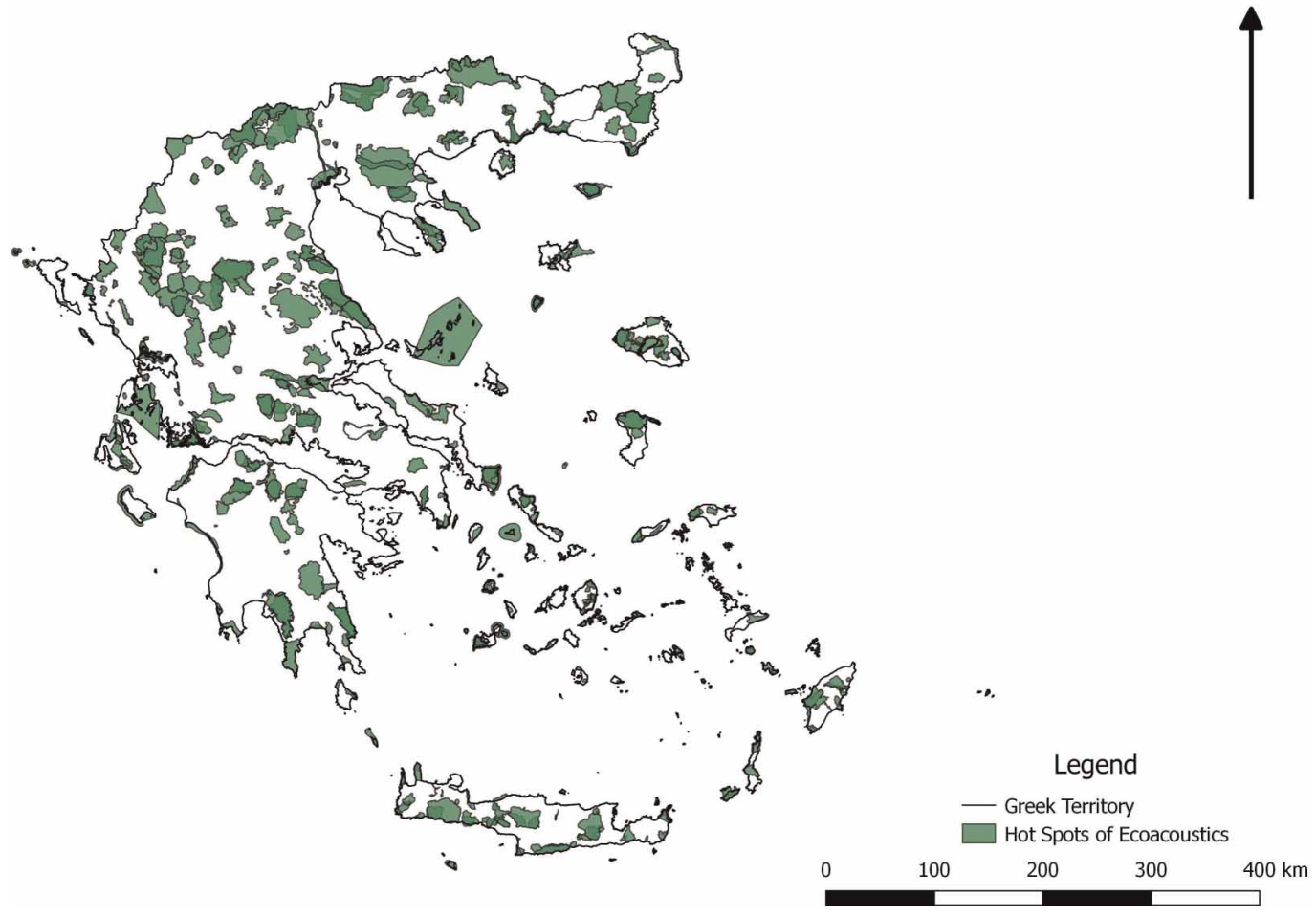

Figure 1. The Greek Natura 2000 Network that alternative could pose as the Hot Spots of Ecoacoustics.

Created using the QGiS mapping software, v. 2.14.7-Essen. 
bioacoustics due to the fact that recognizes sound as an indicator of ecological processes at community levels in contrast to bioacoustics that studies sound as a signal transferring information between individuals (Krause and Farina, 2016). The ecoacoustic discipline evaluates the ecological content of sound in a wide range of spatial and temporal scale in order to address ecological issues such as biodiversity assessment. Although closely related to Bioacoustics, it differs in the fact that sound is recognized as an ecological process at population and community level, while Bioacoustics study's sound as a signal that carries information between individuals (Sueur and Farina, 2015).

Ecoacoustics was developed and used in order to assess biodiversity utilizing soundscape data. The fact that any change in the environment has a direct impact on the acoustic behavior of organisms renders sound as an important behavioral differentiation detection tool on the scale of individual species, populations, communities and landscapes (Krause and Farina, 2016). An example of how ecoacoustics evaluate acoustic communication in a wider scale is the assessment of bird dawn chorus. The specific simultaneous bird vocalization occurs during the first light of day while it differs in terms of intensity and complexity. It is argued that dawn chorus, as an ecoacoustic event, reflects the health and resilience of an ecosystem (Farina et al., 2015).

Numerous ecological indices are being used in order to assess biodiversity. The majority of these indices are related to the diversity and abundance of species/individuals, with several including genetic and phylogenetic characteristics. Examples of the specific kind of indices are the general density, the general abundance, the Simpson and the Shannon indices. Others concern species abundance or diversity and others include functional traits. Nevertheless, traditional sampling methods are considered to be invasive and time consuming. Passive acoustic recordings could be used in order to collect information regarding animal movement, automatic species identification, animal conservation and Rapid Biodiversity Assessment (Depraetere et al., 2012). By applying the basic principles of Bioacoustics and Ecoacoustics along with the use of Ecoinformatics (Sueur and Farina, 2015), all ecoacoustic events which are the functional units of an acoustic environment, could be detected (Farina and Salutari, 2016).

Even though ecoacoustics has proven to be a valuable biodiversity assessment tool, areas that provide a variety of ecoacoustic events are yet to be documented. The Greek protected areas present a great opportunity for such research methods. The ecoacoustics discipline and its tools could be used for biodiversity conservation efforts. Sound recording schemes and the application of the acoustic biodiversity indicators could be proven a valuable tool.

Using the available online datasets (Database on Greek Nature) the areas that include Amphibia, Vertebrae and Birds species were highlighted and conjunctively presented on a map. The database that was used includes all areas, protected or not, that include various Bird species, Amphibia and Vertebrae. Most of these species could pose as an indicator for biodiversity assessment and present a great opportunity for ecoacoustic research. The QGiS mapping software, v. 2.14.7-Essen was used, in order to visualize these areas and set the way for future research. Most of the Greek islands present a high amount of species richness. Nevertheless, continental Greece and especially the coastal areas of the Ionian Sea and of the Peloponnese, also include a great amount of species richness. The northern region of Greece includes a high amount of Amphibia, while North and South Aegean areas include mostly bird communities and Vertebrae (Figure 2).

It is undeniable that the acoustic environment is critical to wildlife and that sounds shape the quality of the overall environment. Traffic noise in otherwise quiet areas (Votsi et al., 2017), can degrade habitat quality (McClure et al., 2013). Remote protected areas similar to Kalloni's bay, are not immune to road traffic noise, due to the fact that traffic corridors produce a significant amount of background noise that propagates over many kilometers (Francis et al., 2017). Furthermore, the issue of background noise in these protected areas is highlighted using as an example the salt pans of Kalloni's bay, located in the Island of Lesvos (North Aegean, Greece). The main goal of the specific article is to highlight the effectiveness of the ecoacoustics discipline in conservation and propose a monitoring network using the non-invasive approach of ecoacoustics.

\section{Methods}

\section{Case Study: Kalloni's Salt Pans}

The Gulf of Kalloni is a small size ecosystem (Kefalas et al., 2016) located in the central part of the Greek Island of Lesvos $\left(39^{\circ} 15^{\prime} \mathrm{N} 26^{\circ} 21^{\prime} \mathrm{E}\right)$. It is a semi-enclosed shallow gulf with a maximum depth $19 \mathrm{~m}$ approximately and a mean depth of $10 \mathrm{~m}$, surrounded by a watershed of about $400 \mathrm{~km}^{2}$ where various human activities take place, mainly urbanization, tourism, and agriculture (Spatharis et al., 2009). The specific area is one of the most 


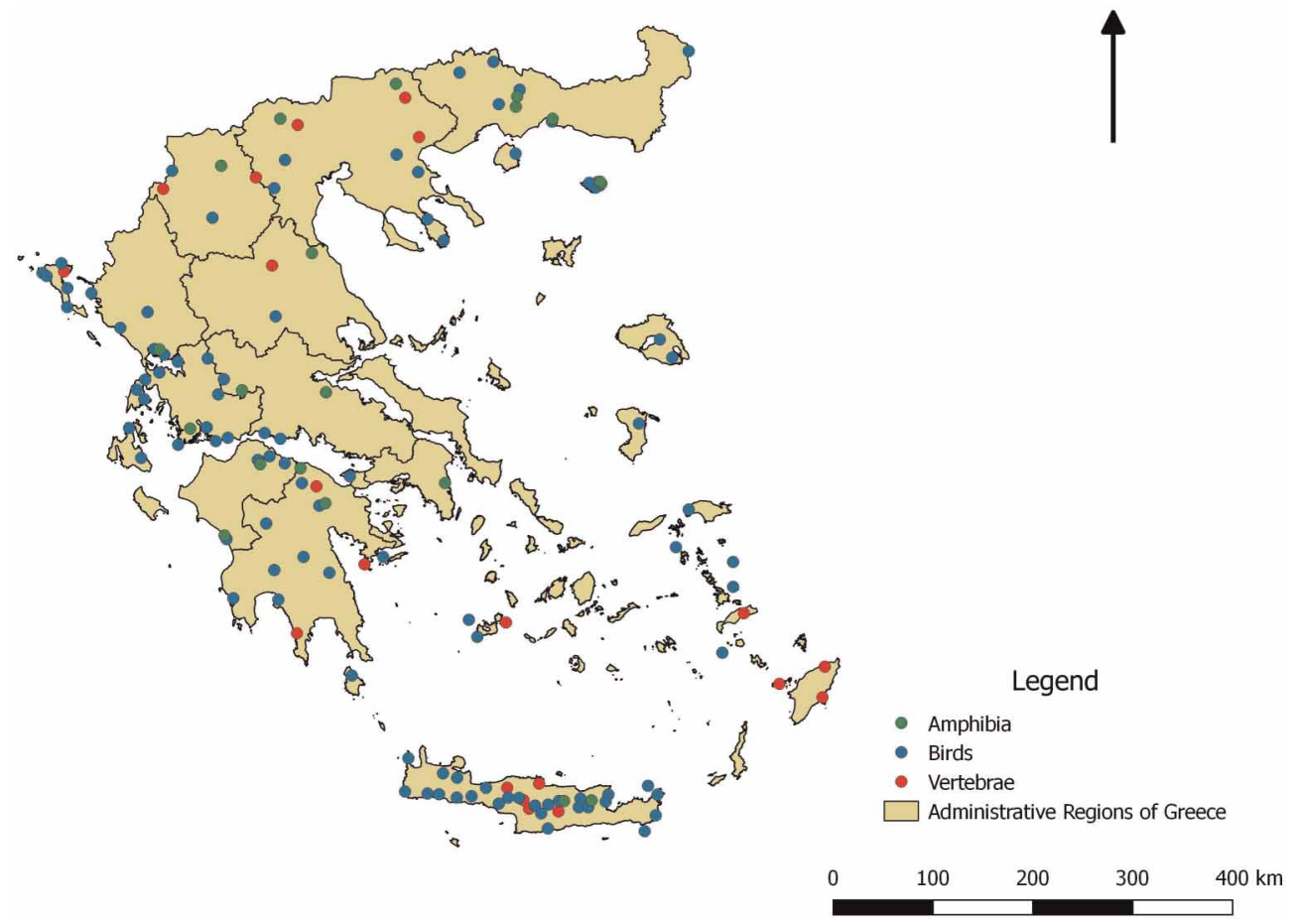

Figure 2. Species distribution of amphibia, birds and vertebrae in the protected areas of Greece.

Created using the QGiS mapping software, v. 2.14.7-Essen.

important fishery centers of Greece. The Gulf of Kalloni is known worldwide for its salt pans which is a human modified habitat populated by shore birds (Sripanomyom et al., 2011).

With the aid of a Landsat ETM+ image of the Kalloni Bay in Lesvos (July 2, 2006) a zoning (Figure 3) was conducted dividing the greater area into three areas of interest corresponding to the three proposed protection zones for inclusion in the "NATURA 2000 Network". The proposed zones are the following:

- Zone A - Protection Core (includes the sea section of the bay and a narrow terrestrial section)

- Zone B - Regulatory Zone (extending around the zone A, is a natural continuation of its ecotypes and a forest ecosystem part)

- Zone C - Peripheral Zone (stretches around zone B and plays a regulatory role - it contains olive groves and forest areas)

One of the most common species present in Kalloni's salt pans, is the Greater Flamingo (Phoenicopterus roseus) with a permanent population, of more than 1,000 individuals. As concluded by Mathevon's research in 1997, background noise could impede the Flamingo's successful communication. Kalloni's salt pans are surrounded by roads were anthropogenic sounds emanate. Anthropogenic sounds could create an inhospitable soundscape for several animal species that become more vulnerable to their predators due to the fact that their attention is distracted (Chan et al., 2010). The mating system of several songbirds and of other vocal species that use auditory signals could be affected by the increase of environmental noise, eroding the strength of sexual selection and possibly their genetic structure (Swaddle and Page, 2007). Soundscapes play a major role in vocal communication in which many animal species rely on. Especially in urban soundscapes the increased background or ambient noise that could mask vocal signals (Mendes et al., 2011) and cause frequency adjustments (Hu and Cardoso, 2010) along with the loss of habitat features could be the reason of disappearance of several urban bird species (Slabbekoorn and Ripmeester, 2008).

Habitat-dependent patterns of sound transmission, the effects of noise, signal perception, and signal interpretation are the major communicational problems that birds and especially song birds (Beckers et al., 2003) as senders and receivers need to adapt to, in order to "get the message across". Previous studies have concluded that communication in noise conditions and the ability to extract information in the presence of background noise could have numerous effects, even in sexual selection (Brumm and Slabbekoorn, 2005). Noisy environments could cause swifts in signal amplitude but also in the minimum frequency domain (Slabbekoorn and Peet, 2003; Nemeth and Brumm, 2009). Therefore, for this study the issue of road traffic noise was studied and noise maps were created. 


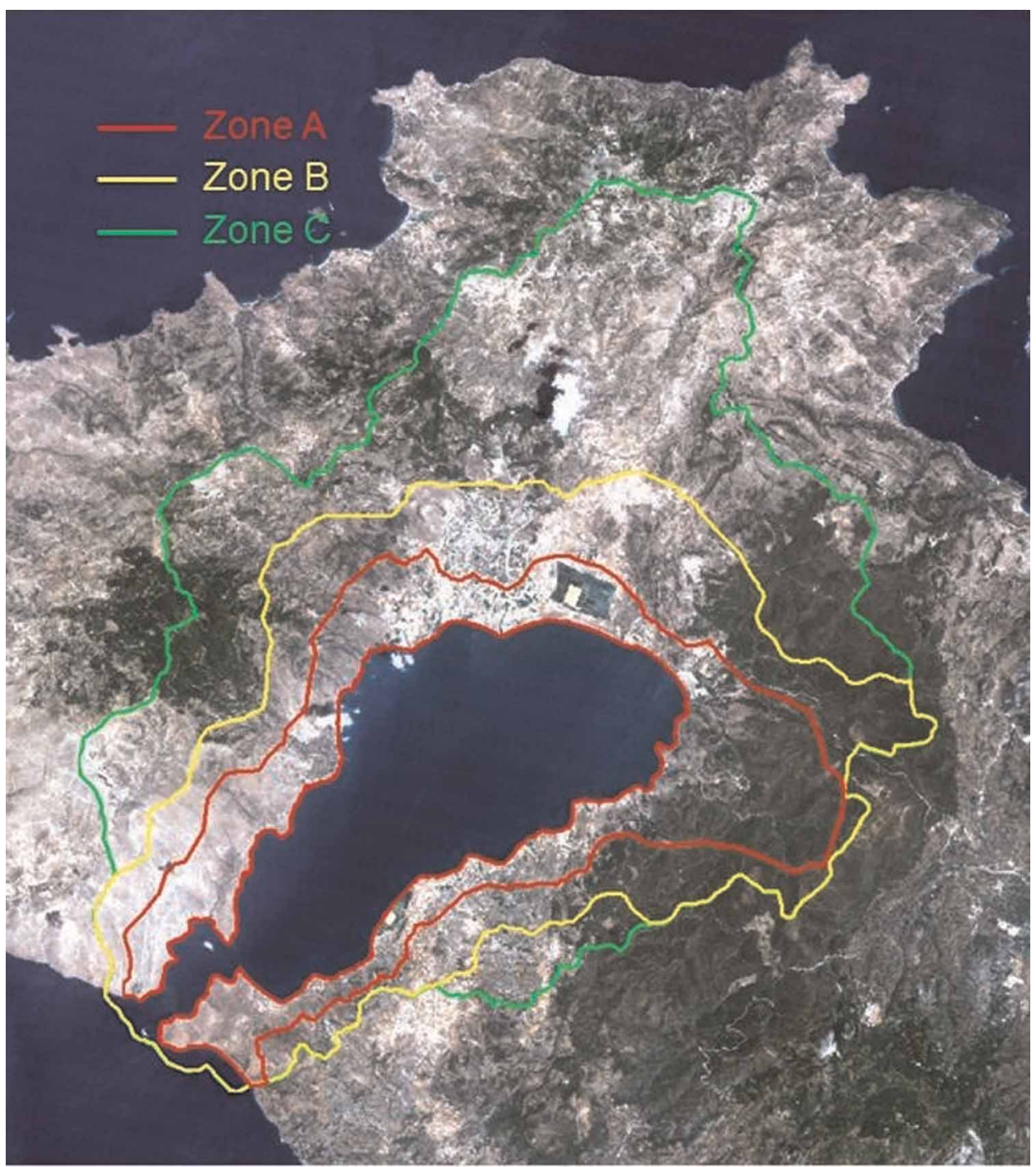

Figure 3. Zones of protection of Kalloni's Bay in Lesvos Island.

Created using the QGiS mapping software, v. 2.14.7-Essen.

Several bird species can be found in Kalloni's salt pans amongst which, Gull-billed Terns (Gelochelidon nilotica), Great egrets (Ardea alba), Little egrets (Egretta garzetta), European herring gulls (Larus argentatus), Great cormorants (Phalacrocorax carbo), Black storks (Ciconia nigra), Greater flamingos (Phoenicopterus roseus), Little stints (Calidris minuta) and Crested larks (Galerida cristata).

Noise measurements were conducted on the side roads and on major road passing above the Kallonis salt pans, during the sound recordings conducted at five check spots (Figure 4). Prior to the recordings made the Sound level meter was calibrated using the standard $94 \mathrm{~dB}$ calibrator as is required for all the class 1 measurement instruments according to the EN61326-1:1997 + A1:1998 specifications. The collection of A Weighting equivalent continuous sound level $\left(\mathrm{L}_{\text {Aeq }}\right)$ aided the creation of a noise map with the use of the CadnaA noise prediction software ('DataKustik', 2017). Furthermore, an isobel map was created in order to present the equal points of sound level. The concept of the isobel map first appeared in Truax's book Acoustic Communication and can be used in order to quantify the baseline acoustic conditions of an area.

Further field work in Kalloni's salt pans involved sound recordings. Audio data were collected during the dawn chorus period (Farina et al., 2015) for 2 consecutive days (May 2018) at the same check spots. Apart from a few street lights located on the nearby major road, no other artificial light sources are present in the area.

For the recordings the multichannel recorder TASCAM DR-680 was used, connected to 2 microphones: a pair of Sontronics STC-1S hypercardioid facing at opposite directions (one towards the salt pans and the other at exactly the opposite area). All channels were recording at $96 \mathrm{KHz} 24 \mathrm{Bit}$ as wave files directly onto SD cards. No changes were done for the whole recording period to neither the hardware itself (recorder, 


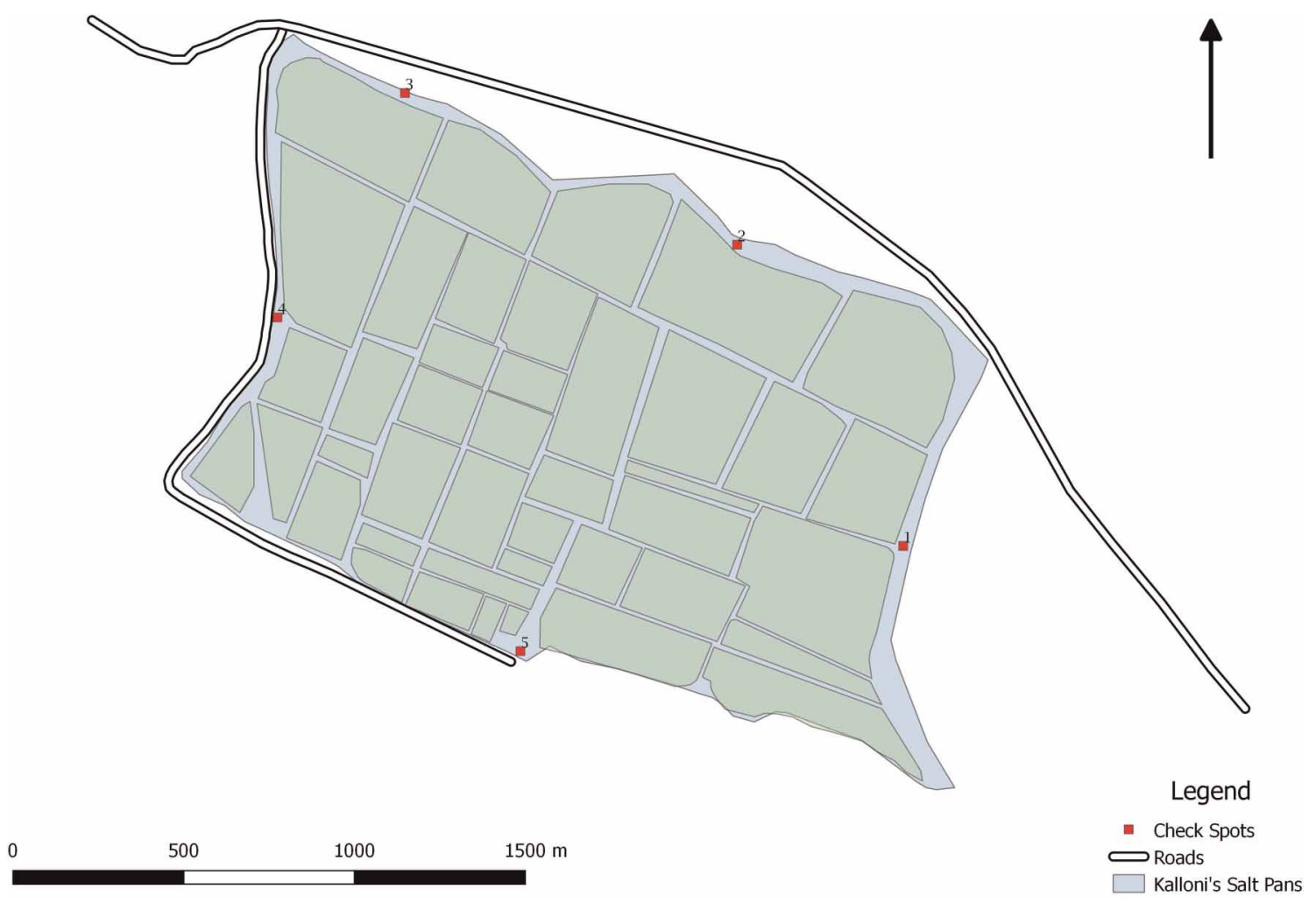

Figure 4. Check spots in Kalloni's Salt Pans.

Created using the QGiS mapping software, v. 2.14.7-Essen.

mics) nor its settings (mic gains, recording levels etc.) in order to ensure the uniform way in which the recordings were conducted.

The recordings took place in five check spots, by researchers from the Acoustic Ecology Laboratory (Department of Environment, University of the Aegean, Mytilene, Lesvos, Greece). The sound data collected, were divided into smaller segments for practical reasons, in order to analyze the audio files more efficiently. The sound files were processed in order to determine the Acoustic Complexity Index (ACI) using the R statistics v. 3.1.3 software (R: The R Project for Statistical Computing, 2017) and the associate packages Seewave, TuneR, Ineq and Soundecology (Sueur et al., 2008; Villanueva-Rivera et al., 2011; Zeileis and Kleiber, 2014).

Finally, similar to the studies conducted by Matsinos et al. (2008) and Mazaris et al. (2009), we used the QGIS software in order to create a thematic sound map. Using inverse distance weighted interpolation (IDW) techniques a cartographic representation for the acoustic complexity (ACI) and the acoustic diversity (ADI) was produced generating an acoustic complexity sound map. The Acoustic Complexity Index (ACI) was calculated and later imported as a feature in the digitized sampling points of the area under consideration.

\section{Results}

The issue of background noise is a well-known phenomenon with various effects on both, human and animal well-being. In order to visualize this problem in Kalloni's salt pans, firstly a digitized map was created using the QGiS mapping software. Using the CadnaA noise mapping software an isobel map (Figure 5) and a noise map (Figure 6) were created. The results indicate high levels of anthropogenic sounds in the form of road traffic noise which is the major pollutant of the area under consideration.

A bird species map was created in order to visualize the distribution of the aforementioned species (Figure 7) as they were observed during the sound recordings. Furthermore, an acoustic complexity map (Figure 8) in combination with the Isobel map was created with the aid of the free open source QGiS software, using an Inverse Distance Weighted (IDW) interpolation technique. The darker orange parts of the acoustic complexity map, represent areas with an elevated acoustic complexity. The above is possible due to the distance from the major road from which environmental noise (road traffic noise) is propagated. Furthermore, the bird species present in the elevated regarding the acoustic complexity index sub areas, are more vocal than the ones present in other less acoustically complex parts of the salt pans. 


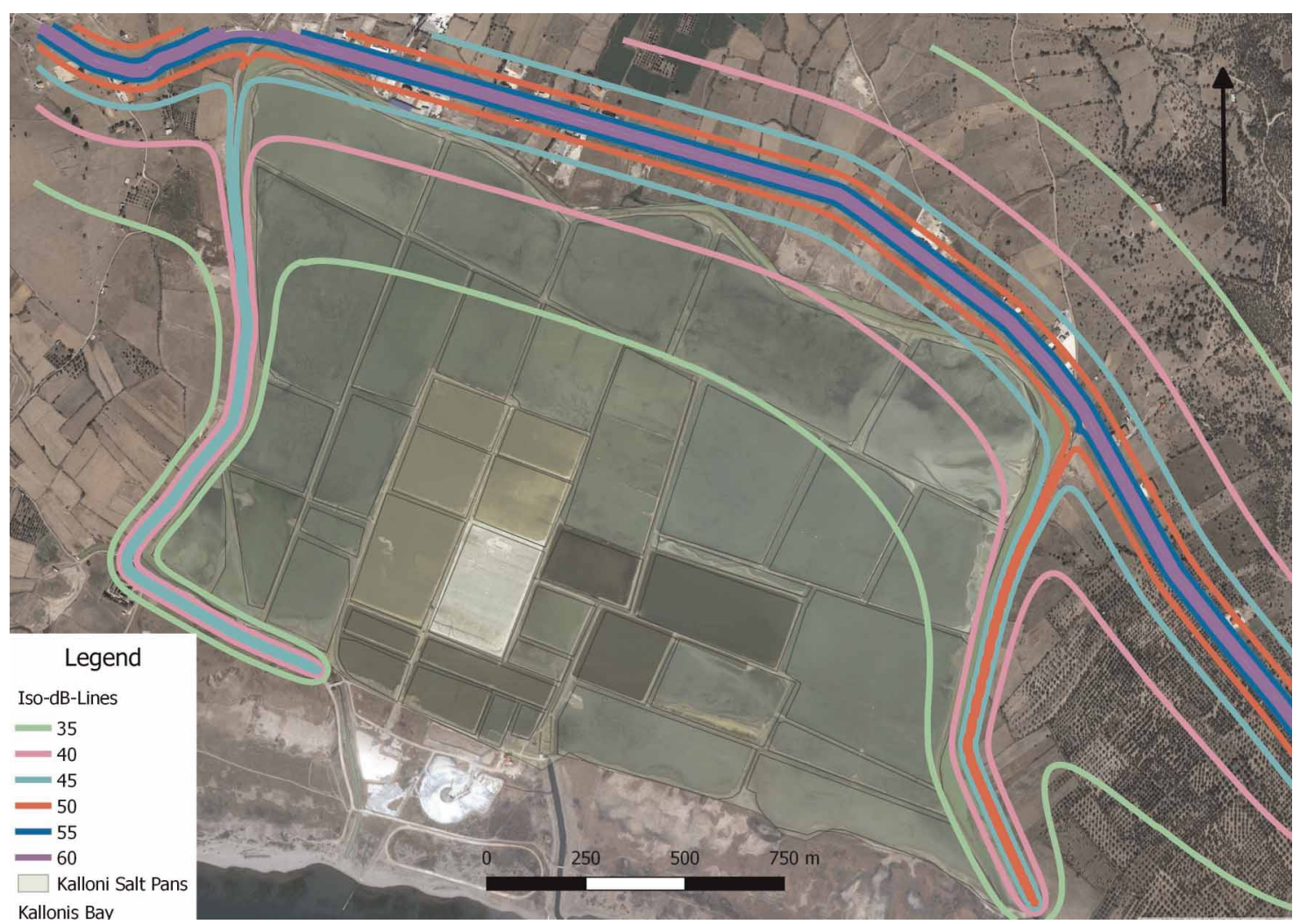

Figure 5. Isobel map of Kalloni's Salt Pans.

Created using the QGiS mapping software, v. 2.14.7-Essen.

\section{Conclusion}

Greece and especially Greek islands similar to Lesvos (North Aegean) stand as a great opportunities for ecoacoustic practice and research. Islands are distinct systems rich in biological indigenousness and ecological eccentricities. They often represent frontiers for several ecological, biological and sociological processes, such as migration, population spreading and human demographic concentration. By studying clusters of islands, biologists view a simpler microcosm of the seemingly infinite complexity of continental and oceanic systems. Islands also offer an

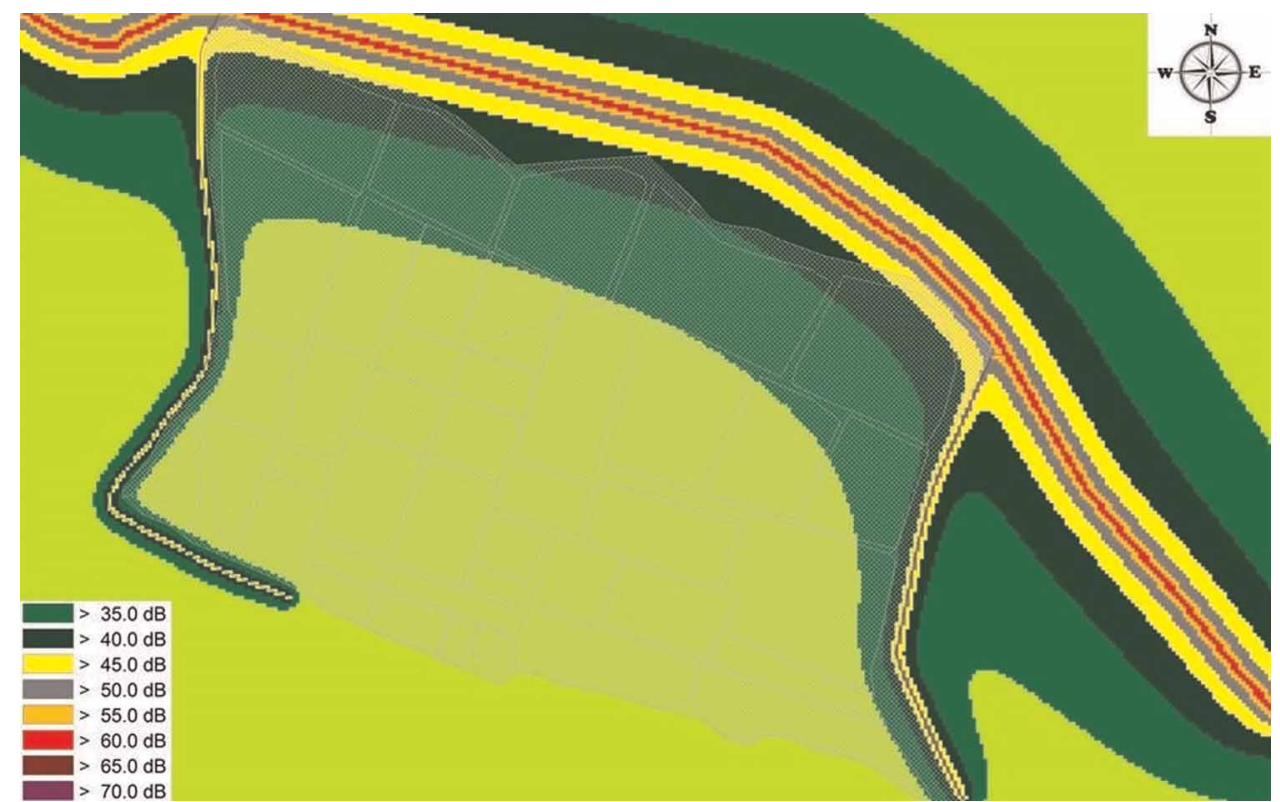

Figure 6. Noise map of Kalloni's Salt Pans.

Created using the QGiS mapping software, v. 2.14.7-Essen and the CadnaA v. 4.3 noise mapping software. 


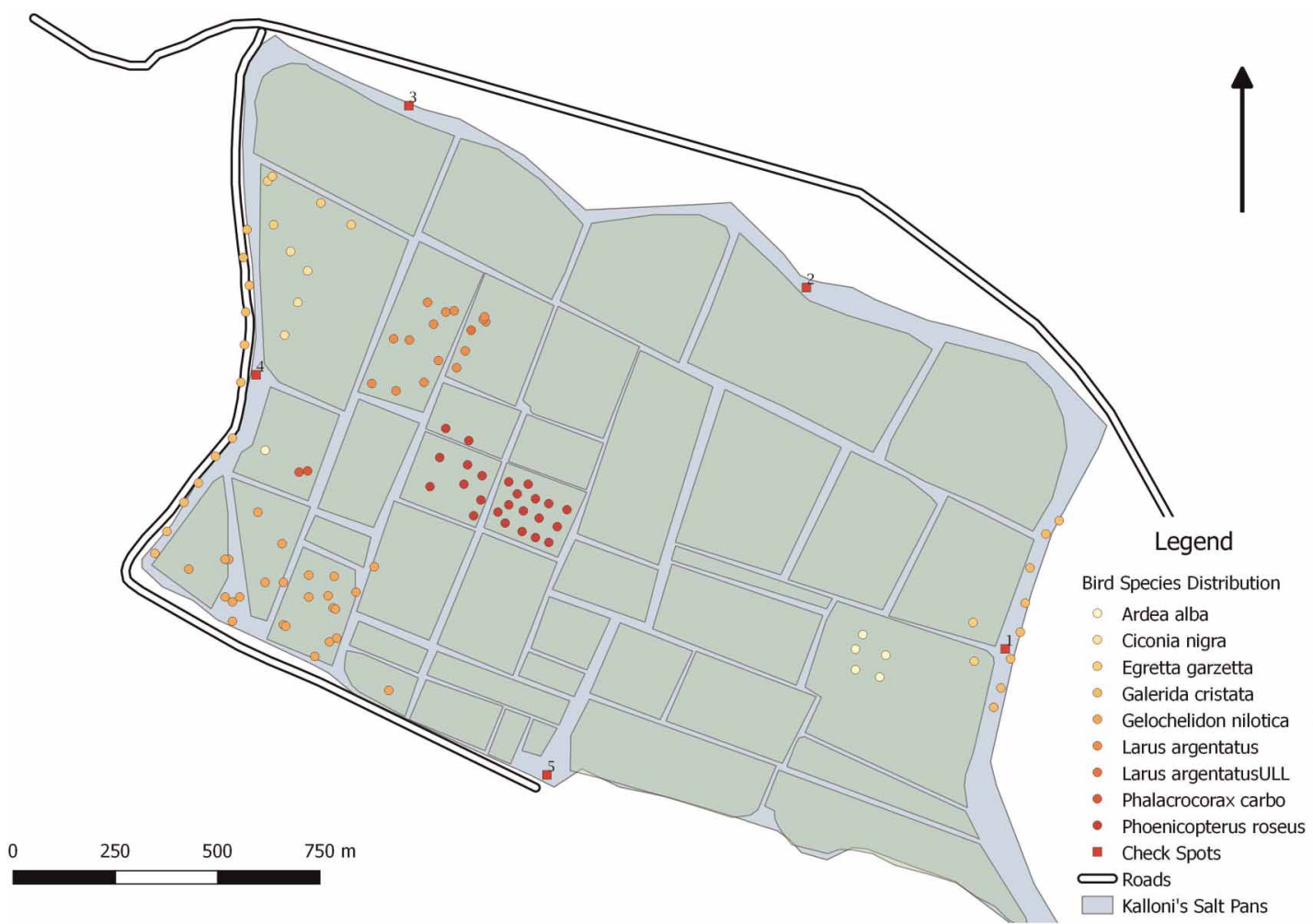

Figure 7. Bird species distribution map.

Created using the QGiS mapping software, v. 2.14.7-Essen.

advantage in being numerous, of multiple shapes and variable sizes, with different degrees of isolation and diverse ecologies. Therefore they provide the perfect laboratories in which the necessary experiments can be conducted by which evolutionary hypotheses can be tested. Islands remain the cradle within which to study

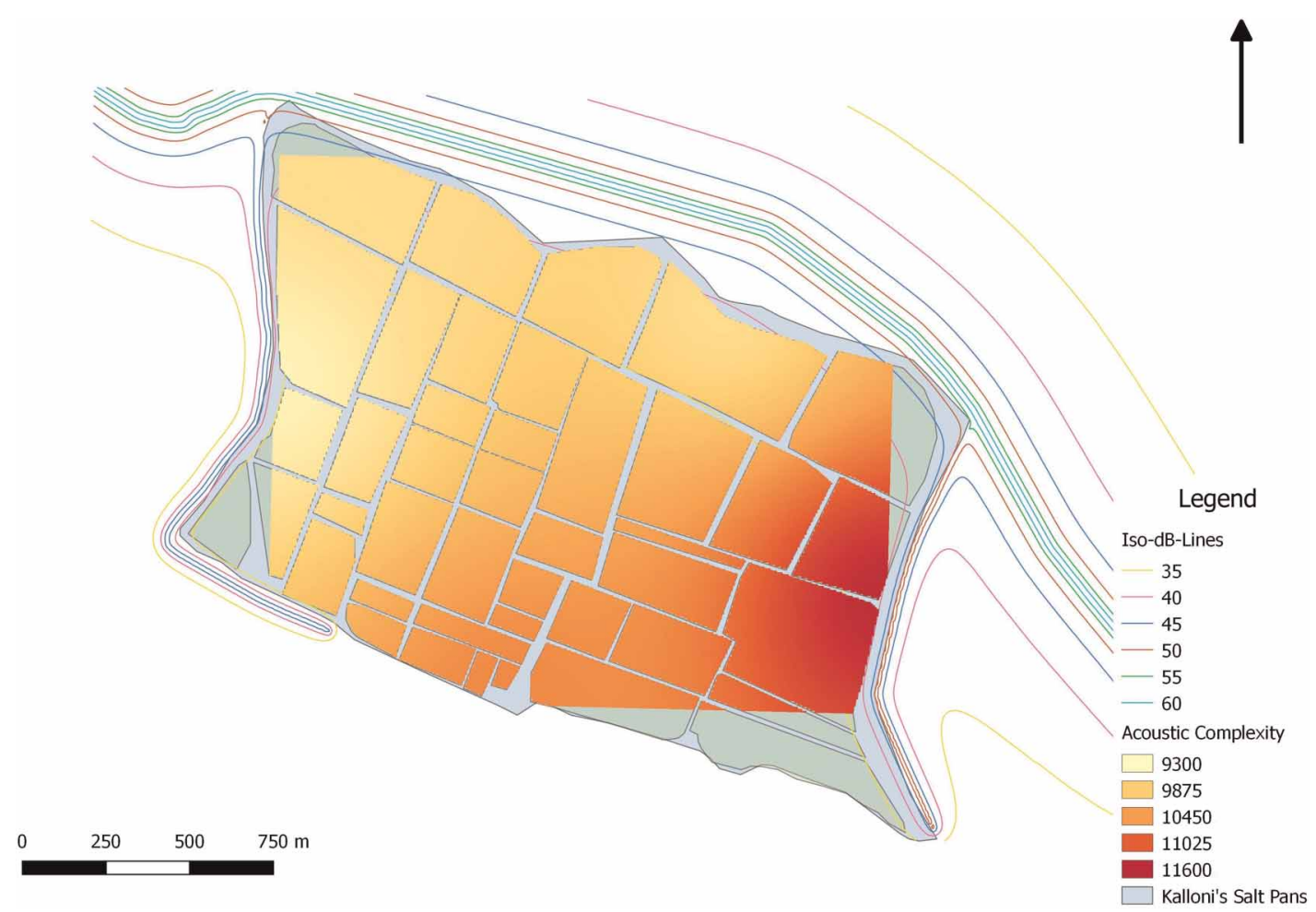

Figure 8. ISOBEL and ACI map of Kalloni's Salt Pans. The darker orange parts represent areas with increased acoustic complexity levels.

Created using the QGiS mapping software, v. 2.14.7-Essen. 
speciations and endemisms, and have represented a source of epistemic-theoretical inspiration for generations of ecologists.

According to observations made in the salt pans of Kalloni, the Greater Flamingos seem to gather in the middle of the available area in order to keep warm during the winter time. Just by visually inspecting the noise, the sound (ACI) map and the Isobel map created it is logical to assume that another reason for this behavior is the road traffic noise that seems to fade away near the center of the area. Here, we propose a monitoring scheme that includes both, soundscape monitoring and noise level monitoring. We strongly suggest that the monitoring of background noise and the soundscape recordings should be applied in all protected areas of Greece. Due to the dissimilarities presented in each area, a different approach should be applied.

The issue of background noise still poses as the biggest problem regarding conservation. The need for a rapid non-invasive biodiversity assessment regarding the protected areas of Europe is undeniable. The ecoacoustics discipline stands as an impeccable tool for assessment and conservation and Greece presents an ideal opportunity for such scientific practice.

\section{Acknowledgements}

The authors of this research would like to thank the anonymous reviewers for their useful suggestions. Furthermore, the authors would like to thank Dimitrios Spatharis and Korkontzila Anastasia for their support.

\section{Funding sources}

This research received funding from the University of the Aegean - Ypatia Scholarship, Greece.

\section{Competing interests}

Yiannis G. Matsinos declares that he has no conflict of interest. Aggelos Tsaligopoulos declares that he has no conflict of interest.

\section{References}

Barredo J. I., Caudullo G., and Dosio A. (2016). Mediterranean habitat loss under future climate conditions: Assessing impacts on the Natura 2000 protected area network. Applied Geography. 75: 83-92. https://doi.org/10.1016/j.apgeog.2016.08.003

Beckers G. J., Suthers R. A., and ten Cate C. (2003). Mechanisms of frequency and amplitude modulation in ring dove song. Journal of Experimental Biology. 206 (11): 1833-1843. https://doi.org/10.1242/jeb.00364

Brumm H. and Slabbekoorn H. (2005). Acoustic communication in noise. Advances in the Study of Behavior. 35: 151-209. https://doi. org/10.1016/S0065-3454(05)35004-2

Buckland S. T. and Johnston A. (2017). Monitoring the biodiversity of regions: Key principles and possible pitfalls. Biological Conservation. 214: 23-34. https://doi.org/10.1016/j.biocon.2017.07.034

Chan A. A. Y.-H., Giraldo-Perez P., Smith S., and Blumstein D. T. (2010). Anthropogenic noise affects risk assessment and attention: the distracted prey hypothesis. Biology Letters. 6 (4): 458-461. https://doi.org/10.1098/rsbl.2009.1081

Database on Greek Nature, Filotis, Accessed: 26 January 2018. https://filotis.itia.ntua.gr

DataKustik (2017). Retrieved 6 October 2018, from http://www.datakustik.com/

Depraetere M., Pavoine S., Jiguet F., Gasc A., Duvail S., and Sueur J. (2012). Monitoring animal diversity using acoustic indices: Implementation in a temperate woodland. Ecological Indicators. 13: 46-54. https://doi.org/10.1016/j.ecolind.2011.05.006

European Commission. Natura 2000 network (2014). Accessed: 25 January 2018. http://ec.europa.eu/environment/nature/natura2000/

Evans D. (2012). Building the European Union's Natura 2000 network. Nature Conservation. 1: 11-26. https://doi.org/10.3897/ natureconservation.1.1808

Farina A. and Salutari P. (2016). Applying the Ecoacoustic Event Detection and Identification (EEDI) model to the analysis of acoustic complexity. Journal of Mediterranean Ecology 14: 3-42.

Farina A., Ceraulo M., Bobryk C., Pieretti N., Quinci E., and Lattanzi E. (2015). Spatial and temporal variation of bird dawn chorus and successive acoustic morning activity in a Mediterranean landscape. Bioacoustics. 24 (3): 269-288. https://doi.org/10.1080/09524622. 2015.1070282

Francis C. D., Newman P., Taff B. D., White C., Monz C. A., et al. (2017). Acoustic environments matter: Synergistic benefits to humans and ecological communities. Journal of Environmental Management. 203: 245-254. https://doi.org/10.1016/j.jenvman.2017. 07.041

Hu Y. and Cardoso G. C. (2010). Which birds adjust the frequency of vocalizations in urban noise? Animal Behaviour. 79 (4): $863-867$. https://doi.org/10.1016/j.anbehav.2009.12.036

Important Bird Areas. (2018). Accessed: 26 January 2018. http://www.ornithologiki.gr/page_in.php?tID=2000.

Jones N., Filos E., Fates E., and Dimitrakopoulos P. G. (2015). Exploring perceptions on participatory management of NATURA 2000 forest sites in Greece. Forest Policy and Economics. 56: 1-8. https://doi.org/10.1016/j.forpol.2015.03.010 
Kefalas E., Castritsi-Catharios J., and Zouganelis G. D. (2016). A study of the benthic community structure of Demospongiae (Porifera) in Kalloni gulf at Lesvos Island (NE Aegean Sea, Greece). Regional Studies in Marine Science. 5: 12-18. https://doi.org/10.1016/j. rsma.2015.12.001

Krause B. and Farina A. (2016). Using ecoacoustic methods to survey the impacts of climate change on biodiversity. Biological Conservation. 195: 245-254. https://doi.org/10.1016/j.biocon.2016.01.013

Mathevon N. (1997). Individuality of contact calls in the greater flamingo phoenicopterus ruber and the problem of background noise in a colony. Ibis. 139 (3): 513-517. https://doi.org/10.1111/j.1474-919X.1997.tb04667.x

Matsinos Y. G., Mazaris A. D., Papadimitriou K. D., Mniestris A., Hatzigiannidis G., et al. (2008). Spatio-temporal variability in human and natural sounds in a rural landscape. Landscape Ecology. 23 (8): 945-959. https://doi.org/10.1007/s10980-008-9250-7

Mazaris A. D., Kallimanis A. S., Chatzigianidis G., Papadimitriou K., and Pantis J. D. (2009). Spatiotemporal analysis of an acoustic environment: interactions between landscape features and sounds. Landscape Ecology. 6 (24): 817-831. https://doi.org/10.1007/ s10980-009-9360-x

McClure C. J. W., Ware H. E., Carlisle J., Kaltenecker G., and Barber J. R. (2013). An experimental investigation into the effects of traffic noise on distributions of birds: avoiding the phantom road. Proceedings of the Royal Society B: Biological Sciences. 280: 20132290. https://doi.org/10.1098/rspb.2013.2290

Mendes S., Colino-Rabanal V. J., and Peris S. J. (2011). Bird song variations along an urban gradient: the case of the European blackbird (Turdus merula). Landscape and Urban Planning. 99 (1): 51-57. https://doi.org/10.1016/j.landurbplan.2010.08.013

Natura 2000. Accessed: 26 January 2018. http://ec.europa.eu/environment/nature/natura2000/

Nemeth E. and Brumm H. (2009). Blackbirds sing higher-pitched songs in cities: adaptation to habitat acoustics or side-effect of urbanization? Animal Behaviour. 78 (3): 637-641. https://doi.org/10.1016/j.anbehav.2009.06.016

Proença V., Martin L. J., Pereira H. M., Fernandez M., McRae L., et al. (2017). Global biodiversity monitoring: From data sources to Essential Biodiversity Variables. Biological Conservation. 213, Part B: 256-263. https://doi.org/10.1016/j.biocon.2016.07.014

R: The R Project for Statistical Computing. Retrieved 29 June 2017. https://www.r-project.org/

Ramsier M. A., Cunningham A. J., Finneran J. J., and Dominy N. J. (2012). Social drive and the evolution of primate hearing. Philosophical Transactions of the Royal Society B: Biological Sciences. 367: 1860-1868. https://doi.org/10.1098/rstb.2011.0219

Slabbekoorn H. and Peet M. (2003). Ecology: Birds sing at a higher pitch in urban noise. Nature. 424 (6946): 267-267. https://doi.org/ $10.1038 / 424267 \mathrm{a}$

Slabbekoorn H. and Ripmeester E. A. (2008). Birdsong and anthropogenic noise: implications and applications for conservation. Molecular Ecology. 17 (1): 72-83. https://doi.org/10.1111/j.1365-294X.2007.03487.x

Spatharis S., Dolapsakis N. P., Economou A. A., Tsirtsis G., and Danielidis D. B. (2009). Dynamics of potentially harmful microalgae in a confined Mediterranean Gulf-Assessing the risk of bloom formation. Harmful Algae. 8 (5): 736-743. https://doi.org/10.1016/j.hal. 2009.03.002

Sripanomyom S., Round P. D., Savini T., Trisurat Y., and Gale G. A. (2011). Traditional salt-pans hold major concentrations of overwintering shorebirds in Southeast Asia. Biological Conservation. 144 (1): 526-537. https://doi.org/10.1016/j.biocon.2010.10.008

Sueur J. and Farina A. (2015). Ecoacoustics: The ecological investigation and interpretation of environmental sound. Biosemiotics. 8 (3): 493-502. https://doi.org/10.1007/s12304-015-9248-x

Sueur J., Aubin T., and Simonis C. (2008). Seewave, a free modular tool for sound analysis and synthesis. Bioacoustics. 18 (2): $213-226$. https://doi.org/10.1080/09524622.2008.9753600

Sueur J., Farina A., Gasc A., Pieretti N., and Pavoine S. (2014). Acoustic indices for biodiversity assessment and landscape investigation. Acta Acustica United With Acustica. 100 (4): 772-781. https://doi.org/10.3813/AAA.918757

Swaddle J. P. and Page L. C. (2007). High levels of environmental noise erode pair preferences in zebra finches: implications for noise pollution. Animal Behaviour. 74 (3): 363-368. https://doi.org/10.1016/j.anbehav.2007.01.004

Turak E., Brazill-Boast J., Cooney T., Drielsma M., DelaCruz J., et al. (2017). Using the essential biodiversity variables framework to measure biodiversity change at national scale. Biological Conservation. 213, Part B: 264-271. https://doi.org/10.1016/j.biocon.2016. 08.019

Villanueva-Rivera L. J., Pijanowski B. C., Doucette J., and Pekin B. (2011). A primer of acoustic analysis for landscape ecologists. Landscape Ecology. 26 (9): 1233. https://doi.org/10.1007/s10980-011-9636-9

Vlami V., Kokkoris I. P., Zogaris S., Cartalis C., Kehayias G., and Dimopoulos P. (2017). Cultural landscapes and attributes of "culturalness" in protected areas: An exploratory assessment in Greece. Science of the Total Environment. 595: 229-243. https://doi.org/10. 1016/j.scitotenv.2017.03.211

Votsi N. P., Kallimanis A. S., and Pantis J. D. (2017). The distribution and importance of quiet areas in the EU. Applied Acoustics. 127: 207-214. https://doi.org/10.1016/j.apacoust.2017.06.007

Zeileis A. and Kleiber C. (2014). ineq: Measuring Inequality, Concentration, and Poverty (Version 0.2-13). https://cran.r-project.org/web/ packages/ineq/index.html 